\title{
Formas de tratamento nominal em cartas de leitor de periódicos de Chapecó, Santa Catarina, Brasil
}

\section{Forms of nominal address from reader's letters in periodicals from Chapecó, Brazil}

Cláudia Andrea Rost Snichelotto ${ }^{1}$, Leila Teixeira da Rosa Strapazzon²

Doutora em Linguística pela Universidade Federal de Santa Catarina (UFSC). Professora Titular-Livre da Universidade Federal da Fronteira Sul (UFFS).

Mestranda em Estudu

Universidade Federal da Fronteira Sul (UFFS). Licenciada em Letras Português e Espanhol pela Universidade Federal da Fronteira Sul (UFFS). E-mail: leila_teixeira11@yahoo.com.br Agradecemos as sugestôes dos pareceristas anônescentes sấo de nossa inteira responsabilidade.
RESUMO: Este artigo apresenta um levantamento de formas de tratamento nominal (FTNs) empregadas em cartas de leitor, publicadas na década de 1950 em Chapecó, Santa Catarina, Brasil. Nosso objetivo é descrever e analisar as FTNs para verificar o valor e as funções atribuídas pelos remetentes das cartas. Com base nos pressupostos teóricos da Teoria da Variação e Mudança Linguística e da Teoria da Polidez Linguística, analisamos uma amostra aleatória de onze cartas do jornal $A$ voz do Chapecó e quatro do jornal $O$ Imparcial, totalizando 15 cartas. Foram identificadas 140 FTNs, dentre as quais, 28 não codificadas e 122 consagradas. Dentre as FTNs não codificadas, predomina a função predicativa, enquanto, nas consagradas, prevalece a função alocutiva. As FTNs não codificadas de caráter pejorativo ofendiam seus alocutores e, consequentemente, aumentavam o distanciamento entre os interlocutores. Observou-se, em razão disso, a baixa recorrência do princípio da cooperação para manter a face positiva nas cartas de leitor investigadas, julgando-se pelo momento histórico de conflitos políticos que Chapecó viveu no período.

Palavras-chave: Formas de Tratamento Nominal; Cartas de leitor; Variação e mudança linguística; Polidez linguística.

ABSTRACT: This article presents the data collection of forms of nominal address (formas de tratamento nominal - FTNs) in reader's letters published in the 1950s in Chapecó, Brazil. Our objective is to describe and to analyze the FTNs in order to verify the values and the functions attributed by the senders of these letters. Based on the theoretical framework of Linguistic variation and change theory, and the Politeness theory, we analyzed eleven (11) random samples of reader's letters from the newspapers $A$ voz do Chapecó and four (4) from the $O$ imparcial, from a number of fifteen (15) letters in total. One hundred and forty (140) occurrences of FTNs were identified, being twenty-eight (28) of non-codified FTNs and one hundred and two (122) of already classified FTNs. Within the amount of classified occurrences of FTNs we could realize a higher number of elocutive functions, while in the non-codified ones there was a predominance of predicative functions. The FTNs of pejorative nature presented the characteristics of offending the alocutors, and as a result, we could perceive an increase of the distance between the partners of the interaction. Furthermore, as a result of this distance, we could notice a low number of occurrences of cooperative principle functions in order to promote a positive representation of the reader's letters investigated in the study, particularly if considered the conflicts of political nature Chapecó faced at that time.

KEYwORDS: Forms of nominal address; Reader's letters; Linguistic variation and change; Politeness language. 


\section{Introdução}

A FTNs são essenciais em uma interação oral, pois constituem uma das ferramentas de que os locutores dispõem para iniciar o contato com seu(s) interlocutor(es). Uma mãe, por exemplo, ao chamar sua filha pelo nome como Juliana não obterá o mesmo efeito que obteria chamando-a por um apelido, como Juli, ou um adjetivo, como filhinha. Para manter a relação harmoniosa e manter a face positiva na interação, não só a maneira como denominamos o nosso interlocutor é manipulada, mas os recursos linguísticos empregados, de forma que se assegure, sempre que possível, a autoimagem dos participantes. Dessa forma, as palavras ditas, normalmente, são suavizadas para que não ofendam o(s) outro(s) participante(s) da interação face a face. Esse fenômeno, denominado polidez linguística, parece dar conta da maneira como as relações sociais ocorrem e se organizam.

Neste artigo, apresentamos um levantamento de FTNs empregadas em cartas de leitor, publicadas na década de 50 do século XX em Chapecó, Santa Catarina, Brasil. Nosso objetivo é descrever e analisar as FTNs para verificar o valor e as funções atribuídas pelos remetentes das cartas.

Diferentemente da atualidade, as cartas de leitor dos jornais daquela época eram utilizadas para contato com o editor, mas sobretudo para assuntos de caráter pessoal, como informar e/ou comunicar-se com amigos e/ou parentes, além de denunciarem problemas sociais. Acreditamos que, por essa razão, as cartas $^{1}$ selecionadas para este estudo guardem registros que se aproximam mais da fala e mantenham o caráter mais pessoal.

\footnotetext{
${ }^{1}$ Estes dois veículos foram escolhidos porque eram esses os únicos exemplares impressos existentes nos locais investigados que dispunham do gênero carta de leitor. Também porque estes jornais eram dirigidos à população do oeste catarinense, em especial à do município de Chapecó e de seus distritos, que atualmente são cidades desmembradas do Velho Chapecó.
}

Após realizarmos um levantamento preliminar de cartas de leitor em jornais de Chapecó, observamos que o uso de FTNs ofensivas a outras pessoas era bastante comum, principalmente quando se queria criticar alguém. Desvendar as causas que conduziram alguns chapecoenses, remetentes das cartas, ao uso de FTNs ofensivas e ignorar a legislação vigente, instigou a realização do presente estudo. A motivação desta pesquisa é, portanto, de cunho linguístico e sócio-histórico.

Organizamos este artigo em três seções, além da introdução e das considerações finais. Na sequência, expomos os pressupostos teóricos que embasam este trabalho. Esta seção se subdivide em três subseções: na primeira, reunimos alguns estudos sobre FTNs (KERBRAT-ORECCHIONI, 2011; GIAUFRET, 2011). Na segunda subseção, são apresentados conceitos básicos da teoria da Polidez Linguística como: face positiva e negativa, atos de ameaça à face e relações simétricas e assimétricas. Na terceira subseção, tratamos de alguns pressupostos da Teoria da Variação e Mudança Linguística. Nas duas seções seguintes, detalhamos a metodologia adotada para esta pesquisa e apresentamos a descrição e a análise das FTNs coletadas nas cartas de leitor da amostra.

\section{Referencial teórico}

\subsection{As FTNs}

As formas de tratamento são um conjunto de expressões utilizadas para se dirigir a outra pessoa participante do discurso (KERBRAT-ORECCHIONI, 1992, p. 15 apud GIAUFRET, 2011). Elas podem ter origem pronominal, como tu, você, senhor ou senhora, ou nominal, por exemplo, Carla, amor, coração, besta, entre outras. As formas de tratamento ultrapassam as barreiras da comunicação; auxiliando na construção de relações entre os participantes do discurso. Por isso, são chamadas de relacionemas. 
Diversos estudos a respeito de FTNs foram desenvolvidos por vários pesquisadores em distintas línguas e sob diferentes perspectivas teóricometodológicas. Entre estes estudos destacamos os de Kerbrat-Orecchioni $(2011)^{2}$ e de Giaufret $(2011)^{3}$, em francês. No português ${ }^{4}$, localizamos, até este momento, os trabalhos de Moraes e Silva (2011), Conceição e Marcotulio (2011), Cintrão (2011), Silva (2011) e Lopes, Rumeu e Marcotulio (2011), para citar alguns.

As FTNs são de extrema importância na interação verbal, principalmente, porque são as primeiras palavras e expressões utilizadas pelos falantes para dar início a uma conversação. 0 que chamou a atenção em sua pesquisa é o fato de que se, em muitas situações comunicacionais, as FTNs estão presentes, em algumas outras, elas praticamente desaparecem. Cita, por exemplo, as situações de entrevista com seus orientandos de mestrado. No momento da entrevista com seu aluno francês (francês-francês), não ocorreu nenhuma FTN, enquanto que, durante a entrevista com o aluno gabonês (francês-gabonês), houve mais de vinte ocorrências.

Estas situações em que não são produzidas FTNs normalmente são atribuídas ao contexto de conversas familiares, devido às relações afetivas e ao apagamento dos nomes próprios. Constata-se também que

[...] Em outros casos, a ausência total de qualquer forma de tratamento nominal se deve ao fato de que não dispomos no nosso repertório de nenhuma forma realmente satisfatória: quando, por exemplo, temos de chamar, no corredor da universidade, alguém que não é nenhum estranho, nem uma pessoa próxima, monsieur [senhor] é muito formal, o seu nome, resultaria por demais familiar, e o sobrenome um pouco brusco [...] (KERBRAT-ORECCHIONI, 2011, p. 20 - grifo da autora)

2 o corpus de pesquisa é constituído por duas entrevistas consecutivas com mesma duração (uma hora e ( em francês e outra em gabonês.

Breve sistematização de estudos já existentes que explicam o funcionamento predicativo das FTNs com ênfase em debates parlamentares.

ropósitos desta seção e dos limites de páginas desta revista, não vamos resenhar cada um desses estudos aqui. Remetemos o leitor a Couto e Lopes (2011).
O francês apresenta grande variedade de FTNs, e a recorrência depende também do uso. É durante o discurso que se concretizam como FTNs. Em determinada situação, pode-se, inclusive, combinar FTNs, por exemplo, Senhor primeiro Ministro ou Senhora juíza.

Outro estudo citado por Kerbrat-Orecchioni (2011) é o de Christine Béal sobre as FTNs no inglês americano em comparação com o francês. Diferentemente dos franceses, os estadunidenses usam as FTNs como uma forma cortês e sem nenhum valor afetivo, principalmente as formas diminutivas dos nomes próprios como, por exemplo, para Emília, Milly ou Lily.

As categorias e as funções das FTNs empregadas na língua francesa foram investigadas por Kerbrat-Orecchioni (2011), que identificou as seguintes categorias: (i) nomes próprios (Paulo, Luiz, Pedro); (ii) formas senhor/ senhora/senhorita (Senhora Elena); (iii) títulos herdados e/ou conferidos (capitão, mestre); (iv) nomes de profissões e funções (garçom, motorista); (v) formas relacionais (termos de parentesco: irmão, papai, titia); (vi) rótulos (ô do boné, você aí de boné); e (vii) formas afetivas com valor negativo (ô loira, imbecil, otário).

As FTNs apresentam as formas consagradas e não codificadas, segundo Giaufret (2011, p. 45-6):

- Formas de tratamento que pertencem a um paradigma consagrado (pronomes, nomes próprios, títulos, termos de parentescos etc.)

- Formas não codificadas; ou seja, que veiculam um certo grau de criatividade; com o objetivo de colocar em prática diferentes operações de linguagem, sobretudo para:

a) Chamar a atenção do interlocutor;

b) Manter o contato com o interlocutor;

c) Escolher um interlocutor entre outros;

d) Dizer algo sobre o interlocutor.

As FTNs consagradas e não codificadas veiculam a função alocutiva cujo objetivo é "[...], instalar ou manter uma relação com o interlocutor" 
(GIAUFRET, 2011, p. 46). As três primeiras categorias de FTNs não codificadas ocorrem em contextos em que se utilizam principalmente vocativos para chamar a atenção do ouvinte. Perret (1968 apud GIAUFRET, 2011) explica que a função alocutiva fundamenta-se principalmente no pressuposto de que, ao utilizar um nome próprio, o locutor pressupõe que este ser é humano e que possui um nome, ou seja, pressupõe-se que ele conheça a pessoa em decorrência do pronunciamento de seu nome. Para exemplificar, o locutor busca reiniciar uma conversa chamando a atenção do seu ouvinte que se dispersou: "Pedro, você está me ouvindo?", além de também impor mudança do interlocutor através da escolha: "Michele, o que você acha?/ Michele o que você tem a dizer sobre isso?" (KERBRAT-ORECCHIONI, 2011, p. 24 - grifos nossos). Ainda, segundo Giaufret, perguntar a uma mulher desconhecida usando a FTN Senhora, onde fica a livraria? implica chamar a atenção de uma desconhecida, referindo-se a ela como interlocutora e com uma informação pressuposta relativa ao sexo feminino.

A quarta e última categoria de FTNs não codificadas possui função predicativa e apoia-se nas informações postas (novas). A função predicativa caracteriza-se por afirmar algo sobre o interlocutor, por exemplo, "Otário ou seu Otário significa que você é um otário (mesmo que relativizado pela enunciatividade: eu acho que você é um otário). 0 enunciador atribui em sua enunciação uma propriedade ao seu alocutor" (GIAUFRET, 2011, p. 50 - grifo da autora). $\mathrm{O}$ interlocutor nem sempre concordará com esta propriedade, mas ela recairá sobre ele e não sobre a relação existente entre locutor e alocutário.

Com base nas funções alocutiva e predicativa, Giaufret (2011) destaca as FTNs denominativas e designativas. No primeiro tipo, o interlocutor conhece a denominação que lhe foi referida, conseguindo identificar-se através dela, portanto, esta informação é pressuposta como, por exemplo, Senhor governador José. Nesse sentido, as FTNs consagradas são classificadas com a função alocutiva e são, portanto, denominativas. Já, as FTNs não codificadas são classificadas como designativas com função predicativa, visto que atribuem uma característica nova ao alocutor. Em Sua besta! revela-se uma pressuposição posta, na qual o locutor atribuiu uma propriedade nova ao alocutor.

Portanto, as FTNs designativas são mais criativas que as denominativas, mesmo que as formas se repitam, como o insulto, ou quando novas formas que estavam em desuso voltam a ser utilizadas. Conclui-se que o insulto é uma FTN designativa, pois "[...] é posta e explícita recaindo sobre o alocutor por meio de uma designação" (GIAUFRET, 2011, p. 51 - grifo da autora).

Os vocativos, por sua vez, ocorrem nas FTNs codificadas e não codificadas e têm funções alocutivas e predicativas, conforme se verá a seguir.

\subsubsection{Os vocativos}

Os vocativos são termos empregados cotidianamente pelos falantes para dirigir-se a seus interlocutores. As gramáticas normativas, como a de Cunha e Cintra (2008), por exemplo, conceituam os vocativos como expressões usadas para chamar pessoas, isto é, situam-se no campo da pragmática. Além de considerar parâmetros pragmáticos, devem-se considerar critérios formais e funcionais (que associam forma e significado) na definição de vocativos. Este último parâmetro é o que se percebe na definição de Cunha e Cintra (2008, p. 175), visto que se constituem como termos acessórios das orações e "[s]ervem apenas para invocar, chamar ou nomear, com maior ou menor ênfase, uma pessoa ou coisa personificada”. Apresentam entonação exclamativa e estão isolados do restante da frase.

Moreira (2013) adota um critério formal ao focalizar o isolamento do vocativo nas sentenças, ou seja, sua independência do restante da oração ${ }^{5}$.

5 Ocorrências citadas por Moreira (2013, p. 11): (1) Filho, isso é só eles é que sabem.(2) Hoje é aniversário da mamãe, João. 
Observa-se que os vocativos ocorrem nas extremidades das sentenças, isto é, no início ou final destas. Portanto, este elemento não influencia sua concordância verbal e é classificado sintaticamente como adjunto.

Os vocativos são extremamente importantes na interação oral, já que, durante esta prática, as pessoas buscam de alguma forma chamar a atenção de seu interlocutor e nomeá-lo. Nos gêneros escritos, os vocativos, principalmente em cartas, e seguindo esta linha, nas cartas de leitor, são elementos que compõem a estrutura própria do gênero epistolar.

Moreira (2008) realizou dois estudos sobre o vocativo no PB. O primeiro deles, em 2008, investiga o uso de vocativos nos séculos XIX e XX, sob a perspectiva da variação e mudança linguística, tendo como corpus peças teatrais. Neste trabalho, a autora constatou mudanças na ordem de emprego dos vocativos. No século XX, há uma ascendência no uso do vocativo posterior à oração (Or + Voc), e a diminuição dos usos em posição anterior à oração $($ Voc + Or) ou entre orações (Or + Voc + Or).

Em trabalho mais recente, Moreira (2013) também analisa a ordem de emprego dos vocativos, e sugere que a interpretação do vocativo pode mudar conforme o tipo de interjeição que o antecede. Há dois tipos de interjeições: aquelas que expressam o estado mental do locutor e as que atuam como vocativos ou não desempenham o papel de "chamamento indireto". “[...] [A]s partículas de chamamento indireto, geralmente precedem um chamamento e, se uma interjeição propriamente dita preceder o vocativo, teremos um destinatário e não um chamamento" (MOREIRA, 2013, p. 1).

Portanto, observar o uso dos vocativos nas cartas contribui para a realização de descrições linguísticas de base empírica. A seguir, articulamse pressupostos teóricos da Teoria da Variação e Mudança Linguística, corrente cujo grande expoente é William Labov.

\subsection{A Teoria da Variação e Mudança Linguística ${ }^{6}$}

Muitos estudos pesquisaram a variação e a mudança em várias línguas7 . Sob esse viés teórico-metodológico da Teoria da Variação e Mudança Linguística, ou Sociolinguística Variacionista, a língua é tomada como um fenômeno de origem social, que está suscetível a mudanças devido a influências internas e externas, e inserida em comunidades de fala.

A concepção de língua sob essa perspectiva se constitui como "[...] uma forma de comportamento social [...], [...] usada por seres humanos num contexto social, comunicando suas necessidades, ideias e emoções uns aos outros" (LABOV, [1972] 2008, p. 215). Dessa maneira, a língua não é simplesmente um instrumento de comunicação, mas vai além, pois envolve sentimentos e emoções dos falantes, que adéquam sua fala ao contexto social e ao tipo de relação profissional, de parentesco ou de amizade que existem em uma conversa.

Em seu texto clássico, Weinreich, Labov e Herzog (2006 [1968]) postulam que todas as línguas sofrem variação, ou seja, a variação é inerente às línguas. Nesse sentido, não se fala da mesma forma em todos os contextos, pois fatores internos e externos determinam o uso da língua. As línguas naturais, como o PB, apresentam variação nos níveis lexical, fonético/fonológico, morfológico, sintático e discursivo. Entretanto, além de aspectos internos, têm-se os externos a ela, "[n]em todas as mudanças são altamente estruturadas, e nenhuma mudança acontece num vácuo social. Até mesmo mudança em cadeia mais sistemática ocorre num tempo e num lugar específicos [...]" (LABOV, [1972] 2008, p. 20), portanto, para os variacionistas, a origem

6 Não temos a pretensão de esgotar, nesta seção, os pressupostos básicos variacionistas, postulados desde a década de 1960. Apenas cremos relevante a contextualização breve de alguns de seus princípios.

Cite-se, por exemplo, o estudo pioneiro de Labov (de 1963 publicado em 1972) sobre a centralização Cite-se, por exemplo, o estudo pioneiro de Labov (de 1963 publicado en
da primeira vogal dos ditongos /ay/ e /aw/ na ilha de Martha'sVineyard 
geográfica e os aspectos sociais são determinantes no modo como o falante utiliza a língua para comunicar-se. Essas diferenças podem ser facilmente percebidas no português falado em diversas regiões do país e, de modo geral, não chegam a comprometer a comunicação entre os interlocutores. Todavia, a análise variacionista revela que as línguas sofrem alterações ao longo do tempo e tais mudanças são percebidas ao se comparar, por exemplo, a fala de pessoas mais velhas com a das mais jovens. Quanto maior a diferença da faixa etária entre os indivíduos, mais diversidade ocorrerá, em alguns fenômenos linguísticos específicos.

Há ainda outras formas de percebermos as mudanças linguísticas nas comunidades como através de textos escritos e falados de outras épocas. Porém, retrocedendo-se cerca de um século, já não é mais possível encontrarmos registros audiovisuais, devido à falta desses recursos nos séculos anteriores.

É sabido que nem todas as situações de variação desencadeiam mudanças na língua. O processo de mudança na língua é possível, conforme Weinreich, Labov e Herzog ([1968] 2006), devido a fatores internos e externos a ela. Um exemplo bastante conhecido de mudança decorrente de fatores externos são as formas de tratamento pronominais para referência à segunda pessoa do singular. De modo bem resumido, inicialmente, no PB, só havia o pronome $t u$, que foi herança latina. Segundo Faraco, 1996, com o surgimento de uma sociedade hierárquica começou a utilizar-se Vossa Mercê, Vossa Majestade para referir a pessoas no tratamento não íntimo entre os membros da aristocracia. Com o passar dos anos, o uso de Vossa Mercê deixou de referir-se a pessoas de alta hierarquia para marcar um tratamento diferenciado entre pessoas que pertenciam a diferentes grupos sociais. Com a intensificação de sua utilização em variados contextos, a mudança ocorreu ao longo dos séculos e houve redução na sua forma: de vosmecê a vossuncê, de suncê a você. Atualmente, em alguns locais do Brasil, utiliza-se até a forma monossilábica cê. Entretanto, na região Sul do Brasil, mais especificamente no estado do Rio Grande do Sul, o tu é ainda é mais frequente que o você. Já em Santa Catarina, conforme Loregian-Penkal (2004), há diferenças significativas entre as regiões catarinenses. Em Lages, por exemplo, o uso de você é mais frequente do que o uso de tu. Além disso, um resultado particularmente importante para este artigo é aquele que diz respeito à cidade de Chapecó, em que os dois pronomes mostram frequências de uso semelhante.

A partir das contribuições apresentadas pela Teoria da Variação e Mudança Linguística, verificaremos se as FTNs localizadas na amostra estão sujeitas à variação decorrente de fatores linguísticos e extralinguísticos. Na próxima subseção, detalharemos a teoria da polidez linguística.

\subsection{A Teoria da Polidez Linguística}

A teoria da polidez linguística possui como principais teóricos fundadores Austin (1975), um dos primeiros a afirmar que a linguagem serve para regular relações sociais, Brown e Levinson (1987), que detalham a noção de face, Grice (1982), que estudou as máximas conversacionais, e Lakoff (1973), pioneiro nesta área, que sugere a existência de duas regras, segundo as quais as pessoas devem ser claras e polidas.

O conceito de "polidez linguística" é de difícil definição mesmo em literatura especializada, conforme alerta Perez (2004). A polidez é definida como uma máxima conversacional, ou seja, como um contrato conversacional de preservação da face. 0 autor explica, em seus estudos, que a existência da polidez linguística em qualquer sociedade ultrapassa as barreiras sociais, sendo ela a base que mantém a harmonia da vida em comunidades: "A polidez é, sem dúvida, um dos elementos basilares da vida em sociedade e, por isso, é considerada como um dos valores socioculturais mais importantes que pode ser expresso por meio da linguagem" (PEREZ, 2004, p. 272). 
Portanto, “[...] princípio da polidez tem por objetivo manter o equilíbrio social e as relações cordiais entre os interlocutores" (SILVA, 1999, p. 116). A autora aponta que, quando duas pessoas participam de uma interação, o primeiro ato que acontece é a quebra do equilíbrio com um simples contato. Duas faces podem ser assumidas pelo indivíduo: a primeira, defensiva, "tendo em vista preservar a própria face [...]" (SILVA, 1999 p. 112) e a segunda, "uma orientação protetora, tendo em vista preservar a face do outro" (SILVA, 1999, p. 112).

Para Brown e Levinson (1987), a noção de face que norteia sua teoria significa "a imagem pública do indivíduo". Desse modo, a polidez deve ser analisada como o ato de proteger a face do indivíduo. Perder, manter ou realçar a face são atos que podem ocorrer durante um processo de comunicação oral, de acordo com as situações de constrangimento ou humilhação a que a face for submetida.

Para que a face sofra estas alterações ou permaneça preservada, observam-se dois tipos de face: a face negativa, configurada como o desejo do indivíduo de não ter suas ações impedidas, inevitavelmente associada à polidez, e a face positiva, que equivale ao desejo humano de ser aprovado e lembrado admiravelmente por sua comunidade social.

Ainda seguindo os pressupostos de Brown e Levinson (1987), há quatro categorias distintas de atos que, dependendo do contexto discursivo, ameaçam a fala, contrariam o desejo do outro, denominados atos ameaçadores da face:

a) atos que ameaçam a face positiva do ouvinte: desaprovação, críticas, insultos, acusações, "raising taboo topics" [levantando temas tabu, tradução nossa];

b) atos que ameaçam a face negativa do ouvinte: pedidos, ordens, sugestões, conselhos, avisos;

c) atos que ameaçam a face positiva do falante: pedidos de desculpa, humilhação, confissão;

d) atos que ameaçam a face negativa do falante: aceitação de ofertas e de agradecimentos (PEREZ, 2004, p. 277 - grifo da autora).
Os riscos de ameaça à face podem ser agravados ou amenizados por três fatores sociais: grau de parentesco entre os participantes; grau de imposição que o falante pode ter sobre seu ouvinte e como cada cultura social observa este grau de imposição. Além disso, deve ser considerado o contexto da situação em que ocorre a conversa.

Para exemplificar, Silva (1999, p. 119) descreve que, na sala de aula, existem constantes ameaças à face tanto do professor quanto do aluno. Ele acrescenta ainda que isto se inicia a partir do lugar profissional que o professor ocupa em relação a seus alunos e também porque os alunos nem sempre estão dispostos a ouvir o seu mestre e adquirir conhecimento com ele. 0 professor, ao incluir no seu discurso "nós", aponta um ato positivo para preservação da face no entanto, o aluno, ao interromper o professor com o enunciado "mas, Zé Paulo", expõe um ato ameaçador, já que, como autoridade da sala, o professor não deve ser interrompido, e sim autorizar o aluno a falar. Somente usando "mas", que é neste contexto uma conjunção adversativa, o aluno contraria a fala do professor, o que pode sinalizar uma ameaça à face do professor. Portanto, na sala de aula, sempre haverá ameaças à face tanto do professor quanto do aluno. Todos os interesses que constituem um indivíduo podem constituir a face, que podem ou não ser realizados pelos outros. Para evitar situações ameaçadoras à face, tanto sua como do outro, o ideal é fugir de situações que possam gerar conflitos.

Há dois tipos de interação possíveis entre os participantes do discurso, $1^{\text {of }}$ interpessoais e $2^{\circ}$ ) transacionais, conforme Barcia (2006), embasado na teoria de Briz (2004). Nas interpessoais "existe, previamente, a disponibilidade para o diálogo e proximidade social entre os interlocutores. São, por isso, relações simétricas, devido a sua estreita ligação com as interações de mais solidariedade" (2006, p. 75). Porém, as relações transacionais têm um objetivo específico, uma finalidade: "Neste caso, a 
distância social é realçada e, por tratar-se de uma relação assimétrica, os direitos e obrigações se apresentam mais determinados e mais estreitamente submetidos às convenções sociais" (2006, p. 75).

As cartas interpessoais possuem como destinatário duas pessoas específicas como, por exemplo, cartas entre familiares, amigos, esposa e marido e namorados. Os temas destas abrangem assuntos de caráter íntimo, pessoal, amistoso, entre outros. As transacionais abarcam como destinatários o redator e pessoas de maior prestígio social, como políticos regionais. Os temas são do interesse do público em geral, que envolvem “questões trabalhistas e jurídicas” (BARCIA, 2006, p. 75).

Brown e Gilman (1960) expõem que exercer poder sobre outra pessoa é ter controle sobre o comportamento do outro, independente do método utilizado, seja ele força corporal, poder econômico, hierarquia familiar, profissão, idade entre outros. Essas relações não são necessariamente estanques, pois um chefe possui mais poder em relação a um empregado subordinado, mas não terá a mesma influência se, no time de futebol em que joga, o seu técnico for o seu empregado subordinado.

A relação de solidariedade é recíproca e os dois interlocutores têm de dividir o mesmo objeto, como argumenta Barcia (2006):

A solidariedade refere-se a relações de proximidade e simetria entre os interlocutores que podem estar baseadas numa relação social real ou percebida/compreendida como tal (Briz, 2004: 80). São relações mais simétricas aquelas em que existe, ou se percebe, igualdade funcional entre os participantes da interação, no que diz respeito a seu papel na interação, assim como igualdade de papéis sociais ou culturais, tais como idade, gênero ou profissão. Também se consideram fatores sócio pragmáticos, para definir as interações de mais proximidade, como aqueles em que os interlocutores têm mais experiências ou saber compartilhado, maior grau de contato (físico ou ocular) e de compromisso afetivo (p. 87 - grifo do autor).
Com base nessa perspectiva, visamos identificar os fatores extralinguísticos que motivam os autores das cartas de leitor a escolherem determinados tipos de FTNs.

\section{Procedimentos metodológicos}

Com o intuito de descrever e analisar as FTNs para verificar o valor e as funções a elas atribuídas, investigamos uma amostra aleatória de cartas de leitor de Chapecó que faz parte de um projeto maior denominado Variação e Mudança no Português do Oeste de Santa Catarina ${ }^{8}$. A coleta foi efetuada no Centro de Pesquisa e Memórias do Oeste Catarinense (CEOM) e na Biblioteca Municipal de Chapecó Neiva Costela, em Chapecó. Identificamos, nos dois semanários, uma seção denominada "A pedido", porém, algumas cartas de leitor foram localizadas fora desta seção. Reconhecido o objeto de pesquisa, fotografaram-se, com câmera digital, as cartas. Na sequência, todos os arquivos foram transcritos, seguindo as Normas de Transcrição de Documentos Manuscritos e Impressos Edição Semidiplomática do Projeto Para a História do Português Brasileiro (PHPB). Posteriormente, ocorreu a catalogação das cartas em arquivos, respeitando a ordem cronológica, partindo das datas de publicações mais antigas para as mais recentes. Foram enumeradas todas as cartas em ordem crescente, denominando seu veículo de publicação, local, edição e fonte de resgate do material.

No Quadro 1 listamos a data de publicação e os respectivos títulos das cartas de leitor da amostra.

8 Projeto financiado com recursos da Chamada Pública FAPESC no 04/2012-Universal. Foi aprovado pelo Comitê de Ética em Pesquisa da UFFS sob o no CAAE 17011413.2.0000.5564. 
Quadro 1 - Data de publicação e título das cartas de leitor de Chapecó

\begin{tabular}{|c|c|c|c|c|c|}
\hline \multicolumn{6}{|c|}{ Cartas de Leitor } \\
\hline \multicolumn{3}{|c|}{ Jornal O Imparcial } & \multicolumn{3}{|c|}{ Jornal A Voz de Chapecó } \\
\hline № & $\begin{array}{c}\text { Data de } \\
\text { publicação }\end{array}$ & Cartas de Leitor & № & $\begin{array}{c}\text { Data de } \\
\text { publicação }\end{array}$ & Cartas de Leitor \\
\hline 01 & $04 / 03 / 1956$ & Covardes & 01 & 08/01/1950 & $\begin{array}{l}\text { Superintendencias das } \\
\text { Empresas Incorporadas } \\
\text { ao Patrimonio Nacional }\end{array}$ \\
\hline 02 & $11 / 05 / 1955$ & $\begin{array}{l}\text { O Dep. Miranda Ramos } \\
\text { responde }\end{array}$ & 02 & $22 / 01 / 1950$ & Carta de uma a outra mãi \\
\hline 03 & $11 / 12 / 1955$ & Atitude de um patife & 03 & $12 / 02 / 1950$ & Atestado de Pobreza \\
\hline 04 & $25 / 12 / 1954$ & A Pedido & 04 & $26 / 02 / 1950$ & $\begin{array}{l}\text { Combate ao } \\
\text { Charlatanismo }\end{array}$ \\
\hline & & & 05 & 05/03/1950 & $\begin{array}{l}\text { Instituto Nacional do } \\
\text { Pinho Serviço do Rio } \\
\text { Uruguai }\end{array}$ \\
\hline & & & 06 & $12 / 03 / 1950$ & Um telegrama \\
\hline & & & 07 & 26/03/1950 & Uma carta \\
\hline & & & 08 & 05/04/1950 & Com a Policia \\
\hline & & & 09 & $16 / 04 / 1950$ & A pedidos uma carta \\
\hline & & & 10 & $28 / 05 / 1950$ & Esclarecimento necessario \\
\hline & & & 11 & 04/06/1950 & $\begin{array}{l}\text { Partido Trabalhista } \\
\text { Brasileiro }\end{array}$ \\
\hline
\end{tabular}

Como se verifica, a amostra analisada é constituída por 15 cartas de leitor, publicadas na década de 1950: onze do jornal $A$ voz de Chapecó e quatro do jornal $O$ Imparcial, embora reconheçamos que não se trata de dados abundantes e que alguns aspectos interacionais não serão evidenciados devido às restrições impostas na transferência da modalidade oral para a escrita.

\section{Descrição e análise das FTNs nas cartas de leitor}

Nesta seção, primeiramente, identificamos, na medida do possível, fatores linguísticos que influenciam o uso das FTNs. Para isso, classificamos as FTNs utilizadas na modalidade de escrita "cartas de leitor" em consagradas e não codificadas, conforme Giaufret (2011) e identificamos as funções alocutiva ou predicativa das FTNs da amostra. Na sequência, controlamos fatores extralinguísticos (sociais e estilísticos) que conduzem a escolha das FTNs utilizadas nas cartas de leitor, demonstrando quem eram os locutores e interlocutores das cartas da amostra e que tipos de relações existiam entre eles: de poder ou solidariedade, simétrica ou assimétrica, conforme expostas por Barcia (2006). Por fim, verificamos nos registros históricos de Chapecó um momento delicado ocorrido na década de 1950 e, como este, de alguma forma, pode ter sido motivador para a escolha das FTNs pelos remetentes chapecoenses nas cartas de leitor.

\subsection{Tipos de FTNs e suas funções nas cartas de leitor de Chapecó}

Nesta subseção, inicialmente, exibimos a classificação dos tipos de FTNs encontradas e, em seguida, descrevemos as funções assumidas pelas FTNs na amostra analisada.

\subsubsection{Classificação das FTNs nas cartas de leitor}

Nesta subseção, apresentamos o total de FTNs utilizadas nas 15 cartas de leitor de nossa amostra, classificando-as, segundo Giaufret (2011), em consagradas e não codificadas, conforme o Quadro 2 a seguir. 
Quadro 2 - FTNs consagradas utilizadas nas cartas de leitor

\begin{tabular}{|c|c|c|}
\hline Jornal & FTNs consagradas & Total parcial \\
\hline O Imparcial & $\begin{array}{l}\text { Snr. Luiz Zambenedeti, Rosa Lunardi Zambenedetti, Digna } \\
\text { esposa, Prefeito Municipal de Xaxim. Dep.Miranda Ramos, } \\
\text { Ilmo. Snr. Diretor de "O Imparcial”, o Snr. Governador } \\
\text { do Estado, S.Excia. o Snr. Governador do Estado, Snrs. } \\
\text { Deputados, V.S, Senhor Diretor, José de Miranda Ramos } \\
\text { Deputado Estadual. Prezados leitores, Sr. Norberto Banher, } \\
\text { O Sr. Bittencourt, Nilo Winck, Oceano Osmar, Enio berthier, } \\
\text { Bittencourt Bittenourt, Enio Berthier. Prezado senhoor, } \\
\text { Ilmo. Snr. Diretor do Jornal “O Imparcial, Arnaldo, Maajeski, } \\
\text { Adão Aguiar Fernandes, V.S. }\end{array}$ & 23 \\
\hline A Voz de Chapecó & $\begin{array}{l}\text { Dr. Gaspar Coutinho, Advogado da Superintendencia, Cel. } \\
\text { Lony De Oliveira Machado, Superintendente. Mãi, Presada } \\
\text { D.F., Nossos filhos, P.J., C., Senhora, Noivinha de meu filho, } \\
\text { Futura sogra de meu outro filho, Mãe, Filha, Soldado, } \\
\text { Marido, Moça, Mulher de militar, Jovem, Moços, Menina } \\
\text { Ponderada,Companheiro, Sr. seu marido, I.T. Waldemar } \\
\text { Tebrin, Arelindo A. Trebin, ZitaBartesi, Frederico Zingler, } \\
\text { Eugenio Trenepoll, Darci de Camargo, Doutor (Dr) Médico } \\
\text { Chéfe, Guarda Sanitário Chéfe. Giro Scopel, Antonio Guedes, } \\
\text { Henrique Brasil, Nomelio Arnaldo, Odilon Martins Simon } \\
\text { Ruas, Paulo Mantavan Jonô Fangugato, Anacleto Agostinho, } \\
\text { Otavio Brasil,Hélio Nasan, Sabino Songalt, Dico Jacob } \\
\text { Maran, Eguiar Sebreiner, Albino Camara, Tasor Osorio, } \\
\text { Vale Alfredo Soefert, Fernandes Lemes, Geraldo Pires, João } \\
\text { Arnaldo Beijamin Daldes, Dalei Arnaldo, Dionisio Verona, } \\
\text { Mario Verine, Renato Volan, Vitorio Fontan, Piragilo } \\
\text { Oliveira Arbelino de Lara, Abeegon Atilho Maseiro, Juvenal } \\
\text { Halvier Germano Fuetan, Alto Veronico, Alfredo Margues, } \\
\text { Adai Leitos Kinbig, FloreloVerona, José Mario Freitas. Ilmo. } \\
\text { Sr. Diretor d' A Voz do Chapecó, V.S, Dr. Darci de Camargo, } \\
\text { Chêfe do Pôsto de Saúde. Ilmo. Sr. Diretor da Voz do Chapecó, } \\
\text { Prezado Senhor, senhores propretarios do cinema local, Um } \\
\text { leitor. Ilmo. Sr. Diretor d A Voz do Chapecó, V.S, Inspetor de } \\
\text { Quarteirão de I Campo-erê, Alichandre Alves dos Santos, } \\
\text { Domingos Batista, Raul Nolasco, Ramielo Fagundes, Osvaldo } \\
\text { Machado, meu filho, a senhora do homem da lei, Sr. Diretor, } \\
\text { José Fagundes. Srn.Dalilo Quintino Perreira, Seu filho, O snr. } \\
\text { Schereiner (cunhado do snr.Danio), Ilustre Dr. Bertaso, S. } \\
\text { Ruas. Senador Dr. Getulio Vargas, Delegado da Zona, José de } \\
\text { Miranda Ramos. }\end{array}$ & 89 \\
\hline \multicolumn{2}{|c|}{ Total de FTNs consagradas } & 112 \\
\hline
\end{tabular}

Observamos a maior incidência na amostra de FTNs consagradas ou nominativas, como pronomes, nomes próprios, títulos, termos de parentescos etc. Citem-se, por exemplo, as expressões "Snr Dalilo Quintino, Senhora, Sr. seu marido, Superintendente, ilustre Dr. Bertaso, Delegado da Zona, sogra, mãe, filha", entre outras. Totalizaram, portanto, em 13 cartas da amostra, 112 ocorrências de FTNs consagradas.

Em seguida, no Quadro 3, exibimos as FTNs não codificadas empregadas nas cartas de leitor.

Quadro 3 - FTNs não codificadas utilizadas nas cartas de leitor

\begin{tabular}{|l|l|c|}
\hline \multicolumn{1}{|c|}{ Jornal } & \multicolumn{1}{|c|}{ FTNs não codificadas } & Total parcial \\
\hline O Imparcial & $\begin{array}{l}\text { Apatacados, senhores feudais de Xaxim, maquiaválicos } \\
\text { adversarios políticos de Zambernedetti, os políticos } \\
\text { apatacados, aos “apatacados" de Xaxim, covardes. Patife, } \\
\text { os mocinhos da qualidade do individuo Gentil Bittencourt, } \\
\text { essa besta, indivíduos inescrupulosos, maquiavélico e } \\
\text { incompetente gerente da Radio Chapecó, vulgo gerênte de } \\
\text { araque, o covarde. }\end{array}$ & 13 \\
\hline A Voz de Chapecó & $\begin{array}{l}\text { Essas duas creaturinhas, Noivinha de meu filho. } \\
\text { Charlatães. Indivíduos meãos, charlatão, os charlatãos. } \\
\text { Mocinhos engraçadinhos, engraçadinhos, taes graçolas de } \\
\text { mau gosto. Dito inspetor, Dita moça, Dito homem da lei. } \\
\text { Dos politiquinhos locaes. Indivíduos inexcrupulosos, os } \\
\text { aproveitadores e confusionistas. }\end{array}$ & 15 \\
\hline Total de FTNs não codificadas & 28 \\
\hline
\end{tabular}

Observamos que, das 15 cartas de leitor coletadas, em nove cartas, sete do jornal A Voz do Chapecó e duas do jornal O Imparcial, foram identificadas 28 FTNs não codificadas. Verifica-se também que, em duas cartas (no 3 e no5), ambas do jornal A Voz de Chapecó, nenhum tipo de FTN foi empregada. Essas duas cartas possuíam como propósito informar o público em geral. A primeira informava as autoridades competentes que o atestado de pobreza somente poderia ser fornecido a pessoas miseráveis, e a segunda um 
anúncio do Instituto Nacional do Pinho informando às delegacias regionais o restabelecimento da exportação de pinho para o mercado platino.

Observamos que todas as FTNs não codificadas apresentavam valor negativo, conforme Quadro 4.

Quadro 4 - FTNs não codificadas com valor negativo nas cartas de leitor

\begin{tabular}{|l|l|}
\hline \multicolumn{1}{|c|}{ Jornal } & \multicolumn{1}{c|}{ Valor negativo } \\
\hline O Imparcial & $\begin{array}{l}\text { Apatacados, senhores feudais de Xaxim, maquiaválicos adversarios políticos } \\
\text { de Zambernedetti, os políticos apatacados, aos “apatacados" de Xaxim, } \\
\text { covardes, patife, os mocinhos da qualidade do individuo Gentil Bittencourt, } \\
\text { essa besta, indivíduos inescrupulosos, maquiavélico e incompetente gerente } \\
\text { da Radio Chapecó, vulgo gerênte de araque, o covarde. }\end{array}$ \\
\hline A Voz de Chapecó & $\begin{array}{l}\text { Charlatães, Indivíduos meãos, charlatão, os charlatãos, Mocinhos } \\
\text { engraçadinhos, engraçadinhos, taes graçolas de mau gosto Dito inspetor, } \\
\text { Dita moça, Dito homem da lei. Dos politiquinhos locaes, indivíduos } \\
\text { inexcrupulosos, os aproveitadores e confusionistas. Essas duas creaturinhas, } \\
\text { Noivinha de meu filho. }\end{array}$ \\
\hline Total de FTNs & \multicolumn{1}{|c|}{28} \\
\hline
\end{tabular}

Essas FTNs ameaçam a face positiva do destinatário com insultos e acusações. De maneira criativa e irônica, os remetentes usam FTNs pejorativas, nas quais aparecem termos no diminutivo e a expressão dito, entre outros fenômenos. Classificam-se, segundo Giaufret (2011), como FTNs designativas. Por exemplo, dos politiquinhos locaes, noivinha de meu filho, essas criaturinhas, dito inspetor, dita moça, dito homem da lei.

Constatamos que as FTNs consagradas e não codificadas coexistem em várias cartas, mais especificamente em nove cartas, e totalizam 94 FTNs. No entanto, uma situação em que o interlocutor que emprega uma FTN consagrada, como ilustríssimo, é diferente de uma em que o interlocutor usa uma FTN irônica e de caráter pejorativo, como mocinhos engraçadinhos.
Ilm. Snr. Diretor da | "Voz do Chapecó. || Nesta Cidade || Prezado Senhor || Peçoagasalho, nas co- | lunas desse valioso jor- | nal, para o seguinte: || Ao senhores propreta- | rios do cinema local, ou | ou a Policia , com refe- | rencia aos abusos que | ultimamente tem se veri- | ficado por mocinhos engraçadinhos, que a todo $\mid$ o momento largam pia- $\mid$ dinhas, assobiam, afinal | não de[ ]xam que o povo | assista um filme como | deveria assistir. (A Voz do Chapecó, Carta 8 - grifo nosso).

Na carta 8, a FTN consagrada Ilm. Snr. Diretor da Voz do Chapecó é usada para referir-se ao diretor do jornal A Voz do Chapecó. Da mesma maneira, encontra-se a FTN mocinhos engraçadinhos, porém esta alude a pessoas que frequentam o cinema da cidade e atrapalham com barulho a concentração de outros espectadores. Nesse enfoque, percebe-se que as FTNs são mescladas entre consagradas e não codificadas nas cartas de leitor, mas seus interlocutores são distintos. Em suma, o número de FTNs consagradas é maior que o de não codificadas, como se pode conferir no Quadro 5.

Quadro 5 - Total de FTNs consagradas e não codificadas

\begin{tabular}{|l|r|}
\hline \multicolumn{2}{|c|}{ Tipos de FTNs } \\
\hline FTNs consagradas & 112 \\
\hline FTNs não codificadas & 28 \\
\hline Total & 140 \\
\hline
\end{tabular}

Apesar de as FTNs consagradas e não codificadas aparecerem mescladas nas cartas de leitor, as não codificadas são encontradas apenas no corpo do texto das cartas. Nas partes que compõe sua estrutura canônica, como cabeçalho, vocativo, despedida e assinatura, não se encontra nenhuma ocorrência de FTNs não codificadas, ou seja, as consagradas predominam nestes elementos da estrutura canônica e no corpo do texto das cartas de leitor. 


\subsubsection{Funções das FTNs nas cartas de leitor}

Identificar as funções das FTNs nas cartas de leitor será o objetivo desta subseção. As FTNs não codificadas e consagradas são classificadas, conforme as pesquisas de Giaufret (2011), em duas funções: alocutiva e predicativa.

Percebemos que a única função empregada nas FTNs não codificadas foi a predicativa, conforme se verifica na carta de leitor 9, do jornal $A$ voz de Chapecó:

A PEDIDOS || PARTIDO TRABALHIS- | TA BRASILEIROII Zona no 1 do Estado de Santa Catarina || Tendo chegado ao nosso conhecimento que | indivíduos inexcrupulosos e aproveitadores estão | tentando organizar sub- diretórios do Partido Tra-| balhista Brasileiro neste Municipio de Chapecó, I sem que para tal estejam devidamente autorizados $(A$ Voz do Chapecó, Carta 9 - grifo nosso).

Ao utilizar a FTN indivíduos inescrupulosos e aproveitadores, o autor pressupõe que estas pessoas não têm princípios morais. Portanto, ele assume uma opinião sobre seus interlocutores, atribuindo a eles uma característica.

No jornal O Imparcial, também se observa a mesma função das FTNs. Na carta número 03, o autor também utiliza a FTN indivíduos inescrupulosos para expor a seu destinatário a afirmação de falta de princípios morais, como se observa a seguir:

|| Neste mesmo jornal, no | dia 27 de Novembro últi- | mo, fiz uma declaração | conforme os prezados lei- | tores poderão verificar a | baixo no sentido de aler- | tar o comércio desta pra- | ça quanto a um inde- | vido do meu nome , por | indivíduos inescrupulosos. || Minha declaração não foi | no sentido de querer ser melhor do que outros, de fa- | zer-me passar por ricaço (O Imparcial, Carta 02 - grifo nosso).

Nesta mesma carta 03, verifica-se ainda a ocorrência de mais cinco FTNs, que são: patife, os mocinhos da qualidade do individuo Gentil
Bittencourt, essa besta, maquiavélico e incompetente gerente da Radio Chapecó, vulgo gerênte de araque, o covarde. Todas elas dizem algo de caráter negativo sobre o interlocutor e, consequentemente, algo que agride a sua face.

Porém, percebemos que, nas FTNs consagradas, a função predominante foi a alocutiva, que apresenta uma informação pressuposta, resumindo-se em chamar a atenção, alternar o interlocutor ou manter o contato, ou seja, são vocativos, como é visível na ocorrência a seguir:

E meu voto, | senhor Diretor, foi pela constitucionalidade do | projeto de lei disposto sobre o PLANO DE | OBRAS E EQUIPAMENTOS. (O Imparcial, Carta 02, grifo nosso).

Feito o levantamento das funções das FTNS empregadas na amostra, passamos aos fatores extralinguísticos que fizeram com que os chapecoenses, autores das cartas, escolhessem 28 FTNs designativas, não codificadas, com função predicativa de valor negativo. Verificar quem foram os autores, qual sua função social, qual o sexo/gênero dos mesmos e que tipo de relação de poder ou de solidariedade existia entre eles é essencial para que se esclareçam os motivos pelos quais usaram insultos explicitamente nos veículos de comunicação.

\subsection{Fatores extralinguísticos que conduzem a escolha das FTNs utilizadas nas cartas de leitor}

A carta de leitor é uma grande revolução na democracia, porque ser cidadão, segundo as palavras de Torres (2008, p. 272), vai muito além de ter poder de voto no processo eleitoral. "Como refere Thorton (1996), as cartas dos leitores refletem as ideias da população em geral, sobretudo daqueles que têm educação suficiente para se sentirem confortáveis em expressar-se através da escrita" (TORRES, 2008, p. 272). 
Nas cartas de leitor, "os leitores têm voz sobre os mais diversos temas, constituindo-se como um dos lugares do jornal onde o cidadão tem a oportunidade de se expressar" (TORRES, 2008, p. 263). Neste enfoque, elas objetivam, como expõe Peterson (2010), opinar, reclamar, solicitar e fazer pedidos sobre assuntos de interesse nacional que circularam na sociedade e consequentemente no meio de comunicação jornalística.

Estes objetivos, na maior parte das cartas de leitor da amostra, se mesclam em informar, alertar, recomendar, ameaçar, reclamar, denunciar, pedir ajuda, esclarecer e retratar fatos na comunidade social de abrangência do veículo de comunicação.

No entanto, a análise revela que, das onze cartas do jornal A voz do Chapecó, apenas duas tinham o propósito de informar e nestas não ocorreram FTNs. Com estes dados, podemos perceber que, quanto mais próximas forem as relações sociais entre locutor e destinatários, maior será o uso de FTNs, pois, quando o objetivo é apenas de informar, os destinatários eram o público em geral, para comunicar algo referente às empresas e nestas cartas não ocorriam FTNs. Quando ocorreram relações de caráter profissional ou em um caso de grau de parentesco as FTNs designativas foram encontradas.

Dessa maneira, detalharemos, nos Quadros 6 e 7, que tipos de relações sociais se estabeleciam entre remetentes e destinatários das cartas de leitor de ambos os jornais em que ocorreu o uso de FTNs não codificadas designativas e consagradas, para que seja observada a relação entre a escolha das FTNs utilizadas e as relações sociais.

Na maioria das cartas, os remetentes são pessoas alfabetizadas, com exceção da carta de leitor número 9 do jornal $A$ Voz de Chapecó, em que se explica, ao final da carta, que o remetente não sabe escrever e, por isso, quem a escreve é outra pessoa no lugar do remetente.

As cartas de leitor são utilizadas para informar, fazer pedidos ou reclamações; independente de seu papel social, sendo assim, como ocorre na carta número 9, na qual José Fagundes, que exerce a profissão de agricultor, dita a carta escrita por Osvaldo Machado endereçada para as autoridades competentes exigindo esclarecimentos sobre o desaparecimento de seu filho preso.

Há dois tipos de interação, segundo Barcia (2006), com base nas teorias de Briz (2004, p. 80-2), 1) entre locutor e interlocutor e 2) as interpessoais e transacionais. Neste enfoque, as cartas de leitor da amostra classificam-se, em sua maioria, como transacionais, pois tinham como objetivo questões de interesse público e seus destinatários incluíam adversários políticos da região, entre outros.

Quadro 6 - Função social de interlocutores das cartas de leitor com ocorrência de FTNs

\begin{tabular}{|c|c|c|}
\hline Jornal & Remetentes & Destinatários \\
\hline \multirow[t]{4}{*}{ O imparcial } & Autor de boletins e propagandas & $\begin{array}{l}\text { Adversários políticos do } \\
\text { prefeito de Xaxim }\end{array}$ \\
\hline & Dep. Estadual José Miranda Ramos & Diretor do Jornal \\
\hline & Proprietário de escritórios & Gerente da Rádio Chapecó \\
\hline & Leitores & Diretor do jornal \\
\hline \multirow[t]{9}{*}{ A voz de Chapecó } & $\begin{array}{l}\text { Superintendente das Empresas Incorporadas } \\
\text { ao Patrimônio Nacional }\end{array}$ & A quem possa interessar \\
\hline & Uma Mãe & Outra Mãe \\
\hline & $\begin{array}{l}\text { Dr. Darci de Camargo Médico Chefe e Guarda } \\
\text { Sanitário }\end{array}$ & $\begin{array}{l}\text { Leitores do município de } \\
\text { Chapecó }\end{array}$ \\
\hline & Grupo de cidadãos de Dionísio Cerqueira & Leitores em geral \\
\hline & Darci de Camargo - Chefe do Posto de Saúde & Diretor do Jornal \\
\hline & Um Leitor & Polícia e Diretor do Jornal \\
\hline & José Fagundes Agricultor & $\begin{array}{l}\text { Diretor do jornal e Autoridades } \\
\text { a quem o caso compete }\end{array}$ \\
\hline & S. Ruas cidadão de Dionísio Cerqueira & Leitores em geral \\
\hline & José Miranda Ramos - Delegado da Zona & Leitores em geral \\
\hline
\end{tabular}


Quadro 7 - Relações de poder e solidariedade nas cartas de leitor

\begin{tabular}{|c|c|c|c|c|}
\hline Jornal & Remetente & Destinatário & $\begin{array}{l}\text { Tipo de } \\
\text { relação }\end{array}$ & $\begin{array}{l}\text { FTNs não codificadas } \\
\text { utilizadas }\end{array}$ \\
\hline \multirow[t]{2}{*}{ O Imparcial } & $\begin{array}{l}\text { Autor de } \\
\text { boletins e } \\
\text { propagandas }\end{array}$ & $\begin{array}{l}\text { Adversários } \\
\text { políticos do } \\
\text { prefeito de } \\
\text { Xaxim }\end{array}$ & assimétrica & $\begin{array}{l}\text { Apatacados, senhores } \\
\text { feudais de Xaxim, } \\
\text { maquiaválicos } \\
\text { adversarios políticos } \\
\text { de Zambernedetti, os } \\
\text { políticos apatacados, aos } \\
\text { "apatacados" de Xaxim, } \\
\text { covardes. }\end{array}$ \\
\hline & $\begin{array}{l}\text { Proprietário de } \\
\text { escritórios }\end{array}$ & $\begin{array}{l}\text { Gerente da } \\
\text { Rádio Chapecó }\end{array}$ & assimétrica & $\begin{array}{l}\text { Patife, os mocinhos da } \\
\text { qualidade do individuo } \\
\text { Gentil Bittencourt, } \\
\text { essa besta, indivíduos } \\
\text { inescrupulosos, } \\
\text { maquiavélico e } \\
\text { incompetente gerente } \\
\text { da Radio Chapecó, vulgo } \\
\text { gerênte de araque, o } \\
\text { covarde. }\end{array}$ \\
\hline \multirow[t]{7}{*}{ A Voz de Chapecó } & Uma mãe & Sogra do filho & simétrica & $\begin{array}{l}\text { Essas duas creaturinhas, } \\
\text { Noivinha de meu filho. }\end{array}$ \\
\hline & $\begin{array}{l}\text { Chefe posto de } \\
\text { saúde }\end{array}$ & $\begin{array}{l}\text { Usuários dos } \\
\text { serviços de } \\
\text { saúde }\end{array}$ & assimétrica & Charlatães. \\
\hline & $\begin{array}{l}\text { Chefe posto de } \\
\text { saúde }\end{array}$ & $\begin{array}{l}\text { Usuários dos } \\
\text { serviços de } \\
\text { saúde }\end{array}$ & assimétrica & $\begin{array}{l}\text { Indivíduos meãos, } \\
\text { charlatão, os charlatãos. }\end{array}$ \\
\hline & Leitor & Polícia & assimétrica & $\begin{array}{l}\text { Mocinhos } \\
\text { engraçadinhos, } \\
\text { engraçadinhos, taes } \\
\text { graçolas de mau gosto. }\end{array}$ \\
\hline & $\begin{array}{l}\text { Um pai de } \\
\text { um cidadão } \\
\text { desaparecido }\end{array}$ & $\begin{array}{l}\text { Autoridades } \\
\text { competentes }\end{array}$ & assimétrica & $\begin{array}{l}\text { Dito inspetor, Dita moça, } \\
\text { Dito homem da lei. }\end{array}$ \\
\hline & Leitor & Leitores & simétrica & Dos politiquinhos locaes. \\
\hline & $\begin{array}{l}\text { Delegado da } \\
\text { zona }\end{array}$ & Leitores & assimétrica & $\begin{array}{l}\text { Indivíduos } \\
\text { inexcrupulosos, os } \\
\text { aproveitadores e } \\
\text { confusionistas. }\end{array}$ \\
\hline
\end{tabular}

Barcia (2006, p. 86) enfatiza que, em toda interação verbal, estão presentes as dimensões sociais do poder e da solidariedade. Essas duas dimensões ajudam na escolha das FTNs utilizadas nas relações sociais. "O poder é concebido, psicológica e socialmente, como o eixo vertical das relações sociais assimétricas ascendentes ou descendentes, e a solidariedade, por outro lado, é compreendida como o eixo horizontal das relações sociais (relações simétricas igualitárias)" (BARCIA, 2006, p. 86 - grifo do autor).

A fim de analisarmos as relações de poder e solidariedade impostas nas cartas da amostra foram observadas as relações simétricas e assimétricas entre remetente e destinatário das cartas de leitor, como pode ser observado no Quadro 7. Em sete das nove cartas de leitor apresentadas, as relações existentes são assimétricas. Em apenas duas há relações simétricas. Nas cartas em que existem relações simétricas, as FTNS que foram utilizadas são respectivamente: essas duas creaturinhas, noivinha de meu filho $e$ dos politiquinhos locaes. Logo, percebe-se a predominância de termos no diminutivo. No entanto, nas outras cartas em que a relação era assimétrica, os termos pejorativos podem ser explicados pelo que cita Rumeu (2004, p. 101): "[0] exercício do poder conduz a uma assimetria nas relações interpessoais que, por sua vez, acarreta uma assimetria no tratamento entre os falantes". Conclui-se que as FTNs utilizadas decorrem dessa relação hierárquica entre os atores do ato comunicativo.

Cabe destacar que somente em uma carta a autora era mulher, embora tenhamos coletado uma amostra aleatória. Porém, isso pode levar à conclusão de que, na década de 1950, as mulheres ainda estavam conquistando direitos, como o poder de opinar na política. A mulher, portanto, ainda era associada à figura de protetora do lar, era ela quem organizava e cuidava da casa e dos filhos. A figura masculina, na época, dominava todos os setores sociais, sendo a família patriarcal. 
Observamos, na carta de leitor a seguir, que a remetente esclarece a sua destinatária o modelo de mulher que sua filha precisará ser ao se casar com um militar, para que a carreira do marido não seja prejudicada e para que não prejudique a vida financeira dos dois. Portanto, a mulher ideal para a sociedade da época era uma mulher que cuidasse dos afazeres domésticos, do marido e filhos de maneira delicada.

Isto facilita a | tarefa que sempre me im- | puz de alertar a jovem | que $P$. $J$. viesse a esco- | lher, para que ela para | o futuro não se sentisse de- | siludida em seu sonho de | moça e para que a sua | ignorancia sobre a vida | de uma mulher de um | militar não venha a pre- | judicar a carreira de seu | marido. || P. J. como soldado está | cingindo a um ordenado | fixo e sem margem a lu- | cros extraordinarios. II De antemão a $C$. saberá I com o que poderá con- I tar depois de casada. Eu | penso que de uma certa | maneira é isso uma van- | tagem que leva a moça | que não se casa com um | civil: ela sabe o que terá | sempre. Mas, é relativa- | mente pouco e a $C$. terá | que ser uma moça equili- | brada e simples ( $A$ Voz do Chapecó, Carta 02 - grifo nosso).

O tema dessa carta, que mostra uma mãe tentando proteger o futuro de seu filho, confirma a função social da mulher, na época, que se restringia a reprodução, a realização de tarefas domésticas e o zelo pelos filhos e marido. Naquele momento histórico, era comum o uso de jornais para a comunicação entre amigos e parentes. Dessa maneira, a publicação da carta 02 no jornal A Voz do Chapecó ocorreu pelo fato de ser uma forma de comunicação entre duas famílias, pois socialmente, em outros assuntos, a mulher não havia conquistado espaço para opinar, sendo oprimida.

Depois de descrever quem eram remetentes e destinatários das cartas de leitor, passamos, a seguir, a apresentar aspectos sócio-históricos de Chapecó na década de 1950. Com isso, pretende-se investigar se alguns acontecimentos contribuíram na escolha das FTNs não codificadas.

\subsubsection{Chapecó na década de 1950: um momento delicado}

A história de Chapecó nas décadas de 1940 e 1950 contribuiu, de forma muito significativa, para desvendar os motivos pelos quais os cidadãos chapecoenses e dos municípios vizinhos publicavam em suas cartas FTNs designativas com valor negativo.

O poder de dominação de Chapecó era de colonizadores e madeireiros até o ano 50. Serafim Bertaso era o colonizador com maior influência entre a população, e o Partido Social Democrático (PSD) se mantinha no poder, representando esta elite. Nas eleições de 50, o PSD foi derrotado pela coligação que englobava os seguintes partidos: "Partido Trabalhista Brasileiro (PTB), União Democrática Nacional (UND) e [...] Partido Progressista (PSP)” (HASS, 2003, p. 43). Ainda, segundo Hass, a igreja católica também se caracterizava como uma entidade que influenciou na formação de valores da população, já que, com tanto trabalho, os colonizadores buscavam, na religião, uma futura recompensa por tanto sofrimento.

A disputa pelo poder na cidade gerava muitos confrontos políticos que se agravaram em 1950. Vários incêndios criminais foram realizados por motivações políticas antes desta data. Porém, nenhum deles indignou tanto a população quanto o incêndio da Catedral Santo Antônio de Chapecó em 04 de outubro de 1950. Tal incêndio desencadeou um processo de caça e punição aos culpados, pois para um povo que tinha a igreja como consolo ao seu sofrimento, queimá-la foi brutal. Armando Lima era um gaúcho e possuia um salão de festas em Chapecó, ele foi acusado injustamente pelos autores do crime Ruani e Ivo de Oliveira Paim de ser cumplice. Seu irmão, Orlando Lima que residia em Iraí Rio Grande do Sul, deslocou-se a Chapecó para tentar ajudá-lo, mas também foi preso. E então, sob tortura de um delegado, confessaram o crime.

Com medo de ser exonerado do cargo pelos seus abusos autoritários, que incluíram tortura, o delegado organizou um motim para eliminar as provas de 
suas infrações, eliminar as testemunhas e fazer parecer um linchamento. Este linchamento ocorreu em 17 de outubro de 1950, quando aproximadamente 200 homens invadiram a prisão, mataram quatro prisioneiros, incluindo os irmãos Lima, com tiros e golpes de facão, e depois arrastaram seus corpos para o pátio e queimaram-nos.

Por isso, neste contexto de conflitos políticos, como afirma o Hass (2003), viver não era simples. A lei que predominava era a que beneficiava os grupos manipuladores da cidade. 0 processo de linchamento foi apenas um reflexo da organização da cidade e, consequentemente, do comportamento das autoridades que pensavam apenas no seu próprio benefício utilizando-se da manipulação da população para dominar a cidade.

A imprensa, em geral, utilizava-se de seu poder de divulgação para “[...] influir na opinião pública da comunidade, [...] atacando seus adversários políticos e se projetando favoravelmente na localidade" (HASS, 1977, p. 161). Hass (2003) explica que o PSD possuía maior influência na imprensa por meio do jornal A voz do Chapecó e da Rádio Sociedade Oeste Catarinense, enquanto UND e PTB utilizavam-se do veículo O Imparcial e, anteriormente, do Jornal do Povo.

Com base nestas informações, o uso de insultos nas cartas de leitor do jornal $\mathrm{O}$ imparcial e A Voz do Chapecó pode ser interpretado como um reflexo da conduta social de chapecoenses naquela década. Esta conduta refletia os conflitos políticos e era influenciada pela imprensa local. Porém, no Brasil, o Art. 139 do Código Penal Brasileiro, criado pelo Decreto-lei no 2.848, de 07 de dezembro de 1940, adverte sobre a ofensa à imagem social de outra pessoa: "Difamar alguém, imputando-lhe fato ofensivo à sua reputação: Pena - detenção, de 3 (três) meses a 1 (um) ano, e multa”. Nesse sentido o respeito ao outro é exigido por lei, independente do tipo de relação que mantenham entre si, para que a vida social ocorra harmonicamente.

Vale salientar que as cartas do jornal A voz do Chapecó estão datadas entre 08 de janeiro de 1950 e 04 de junho do mesmo ano. Sendo assim, as mesmas foram publicadas antes do incêndio e do linchamento. Todavia não deixam de estar inseridas em um contexto onde prevaleciam "[...] atritos e lutas políticas [...], diante dos diferentes interesses de grupos em choque pela afirmação do espaço de dominação local" (HASS, 2003, p. 42-3), nos quais eram usados vários métodos para se manter no poder, sendo eles lícitos ou ilícitos. Podem-se observar os conflitos políticos na carta abaixo:

A PEDIDOS || PARTIDO TRABALHIS- | TA BRASILEIROII Zona no 1 do Estado de Santa Catarina || Tendo chegado ao nosso conhecimento que | indivíduos inexcrupulosos e aproveitadores estão | tentando organizar subdiretórios do Partido Tra-Ibalhista Brasileiro neste Municipio de Chapecó, | sem que para tal estejam devidamente autorizados: (A Voz do Chapecó, Carta 09 - grifo nosso)

Já, o jornal 0 Imparcial foi fundado em 25 de fevereiro de 1951, logo após o linchamento ter ocorrido. As cartas datam entre 11 de dezembro de 1955 a 04 de março de 1956, anos depois do linchamento. No entanto, ainda é possível perceber a presença das divergências políticas em Chapecó e também em outros municípios que foram desmembrados dele, por meio das cartas.

Entretanto, adversários políticos do | snr.Zambenedetti, que de modo algum | não chegam aos pés em caráter e prestigio | junto á população, valendo-se do dinheiro | e dos apaniguados servis de que dispõem, | tudo vem fazendo as tentativa vã de som- | brear o prestigio político do snr.Zambene- | detti, lançando mão dos mais sórdi- | dos, próprios do quilate rasteiro e mesqui- $\mid$ nho dos ditos "apatacados" (O Imparcial, Carta 01 - grifo nosso).

Nessa situação de rivalidade política vivida pelos chapecoenses, na década de 1950, a polidez linguística não se concretizou em muitas cartas de leitor. O que fica visivelmente perceptível, segundo pressupostos de Brown e Levinson, eram os atos de ameaça à face positiva dos destinatários das cartas, por meio de críticas e insultos que incluíam as FTNs negativas. 


\section{Considerações finais}

Apresentaram-se aqui as FTNs utilizadas na amostra de cartas de leitor de jornais, da década de 1950, do município de Chapecó. Identificaram-se 28 FTNs não codificadas e 112 FTNs consagradas.

Examinando os fatores linguísticos, verificamos que, das 28 FTNs não codificadas, todas possuíam valor negativo. Dentre essas encontram-se o uso do diminutivo e do termo dito, ratificando assim a presença de formas pejorativas e ofensas aos destinatários das cartas. Quanto a suas funções, observamos que a função predicativa predominou nas FTNs não codificadas, enquanto nas consagradas a predominância foi da função alocutiva. Logo, o uso de FTNs de caráter pejorativo é recorrente na amostra e isso levou-nos a investigar por que motivo este fato ocorreu. Outro aspecto observado foi que a escolha das FTNs dependeu também do tipo de relação social estabelecida entre remetentes e destinatário quanto mais próximos, maior será o uso de FTNs. Se o vínculo entre os interlocutores era assimétrico, o uso de formas pejorativas era mais recorrente, causando o distanciamento entre os participantes do discurso.

Analisando os fatores extralinguísticos (sociais e estilísticos) que conduziram a escolha das FTNs utilizadas nas cartas de leitor, percebeu-se que a ocorrência de divergências políticas em Chapecó pode ter influenciado a conduta dos habitantes, que, devido ao contexto conturbado de brigas e disputas, posicionavam-se de modo a tentar atingir a face de seus adversários, ofendendo-os por meio de insultos.

Dessa maneira, sinalizando o encaminhamento de estudos futuros, sugerimos que o uso do termo "dito" e de FTNs no diminutivo podem ser explorados em trabalhos posteriores, constituindo-se como objetos para pesquisas futuras.

\section{Referências}

AUSTIN, John L Langshaw. How to do things with words. 2. ed. Cambridge, Mass.: Harvard University Press, 1975.

BARCIA, Lucia Rosado. As Formas de Tratamento em Cartas de Leitores Oitocentistas: peculiaridades do gênero e reflexos da mudança pronominal. 2006. 142 fl. Dissertação (Mestrado em Língua Portuguesa) - Universidade Federal do Rio de Janeiro, 2006.

BRASIL. Lei $n^{\circ}$ 2.848, de 7 de dezembro de 1940. Disponível em: <http http://www. planalto.gov.br/ccivil_03/decreto-lei/del2848.htm>. Acesso em: 4 abr. 2014.

BROWN, Penelope; LEVINSON, Stephen C. Politeness: some universals in language usage. Cambridge: Cambridge University Press, 1987.

CINTRÃO, Heloisa Pezza. Pensando as formas de tratamento a partir da semiótica e a semiótica a partir das formas de tratamento. In: COUTO, Letícia Rebollo; LOPES, Célia Regina dos Santos (Org.). As formas de tratamento em português e em espanhol variação, mudança e funções conversacionais. Rio de Janeiro: Editora da Universidade Federal Fluminense, 2011. p. 457-71.

CONCEIÇÃO, Adriana Angelita da; MARCOTULIO, Leonardo Lennertz. História e linguagem: um diálogo sobre o tratamento na prática epistolar luso-brasileira setecentista. In: COUTO, Letícia Rebollo; LOPES, Célia Regina dos Santos (Org.). As formas de tratamento em português e em espanhol variação, mudança e funções conversacionais. Rio de Janeiro: Editora da Universidade Federal Fluminense, 2011. p. 213-42.

COUTO, Letícia Rebollo; LOPES, Célia Regina dos Santos (Org.). As formas de tratamento em português e em espanhol variação, mudança e funções conversacionais. Rio de Janeiro: Editora da Universidade Federal Fluminense, 2011.

CUNHA, Celso; CINTRA, Lindley. Nova gramática do português contemporâneo. 5. ed. Rio de Janeiro: Lexikon, 2008.

FARACO, Carlos Alberto. O tratamento você em português: uma abordagem histórica. Fragmenta, v. 13, p. 51-82, 1996.

GIAUFRET, Anna. De Mário a Otário: As formas de tratamento nominais - modelos de função alocutiva ou predicativa? Tradução de: Janaína França e Márcia Atálla Pietroluongo. In: COUTO, Letícia Rebollo; LOPES, Célia Regina dos Santos (Org.). As formas de tratamento em português e em espanhol variação, mudança e funções conversacionais. Rio de Janeiro: Editora da UFF, 2011. p. 45-58. 
GRICE, H. Paul. Lógica e Conversação. In: DASCAL, Marcelo (Org.). Pragmática-problemas, críticas, perspectivas da linguística - biografia. Tradução de: João Vanderley Geraldi. Campinas: Unicamp, 1982. 4 v. (Coleção Fundamentos Metodológicos da Linguística).

HASS, Monica. O linchamento que muitos querem esquecer. Chapecó: Argos, 2003.

KERBRAT-ORECCHIONI, Catherine. Modelos de variações intraculturais e interculturais: as formas de tratamento nominais em francês. Tradução de: Fernando Afonso de Almeida e Letícia Rebollo Couto. In: COUTO, Letícia Rebollo; LOPES, Célia Regina dos Santos. (Org.). As formas de tratamento em português e em espanhol variação, mudança e funções conversacionais. Rio de Janeiro: Editora da UFF, 2011. p. 19-46.

LABOV, William. Padrões sociolinguísticos. Tradução de Marcos Bagno, Marta Pereira Scherre e Caroline Cardoso. São Paulo: Parábola, 2008. [Original em inglês].

LAKOFF, Robin. Language and Woman's Place. Language in Society, v. 2, n. 1, p. 45-80, Apr. 1973.

LOPES, Célia Regina dos Santos; MARCOTULIO, Leonardo Lennertz; RUMEU, Márcia Cristina de Brito. O tratamento de bilhetes amorosos no início do século XX: do condicionamento estrutural ao sociopragmático. In: COUTO, Letícia Rebollo; LOPES, Célia Regina dos Santos (Org.). As formas de tratamento em português e em espanhol variação, mudança e funções conversacionais. Rio de Janeiro: Editora da UFF, 2011. p. 315-348.

LOREGIAN-PENKAL, Loremi. (Re)Análise da referência de segunda pessoa na fala da região sul. 2004. 260f. Tese (Doutorado em Letras) - Universidade Federal de Paraná, 2004.

MORAES, João Antonio de; SILVA, Hayla Thami. A entoação de vocativos e apostos no portiuguês do Brasil. In: COUTO, Letícia Rebollo; LOPES, Célia Regina dos Santos (Org.). As formas de tratamento em português e em espanhol variação, mudança e funções conversacionais. Rio de Janeiro: Editora da UFF, 2011. p. 103-124.

MOREIRA, Juliana Costa. O vocativo na interface sintaxe-pragmática. 2013. $156 \mathrm{fl}$. Tese (Doutorado em Estudos Linguísticos) - Universidade Federal de Minas Gerais, 2013.

MOREIRA, Juliana Costa. O vocativo no português brasileiro nos séculos XIX e XX: um estudo de mudanças linguísticas. 2008. $111 \mathrm{fl}$. Dissertação (Mestrado em Estudos Linguísticos) - Universidade Federal de Minas Gerais, 2008.

PEREZ, Taísa Oliveira de. Polidez e linguagens: perspectivas. Revista Signótica, v. 16, n. 2, p. 271-288, dez. 2004
PETERSON, Maria Saldanha. A ordem dos clíticos pronominais em lexias verbais simples e complexas em cartas de leitor: uma contribuição da sociolinguística variacionista. 2010 209 fl. Dissertação (Mestrado em Letras Vernáculas) - Universidade Federal do Rio de Janeiro, 2010

RUMEU, Márcia Cristina de Brito. A implementação do 'Você' no Português Brasileiro Oitocentista e Novecentista: Um estudo de painel. 2008. 279 fl. Tese (Doutorado em Letras Vernáculas) - Universidade Estadual do Rio de Janeiro, 2008.

SILVA, Luiz Antônio. Formas de tratamento, cortesia y diversidade cultural en portugués In: COUTO, Letícia Rebollo; LOPES, Célia Regina dos Santos (Org.). As formas de tratamento em português e em espanhol variação, mudança e funções conversacionais. Rio de Janeiro: Editora da UFF, 2011. p. 303-314.

SILVA, Luiz Antônio da. Polidez na interação professor/aluno. In: PRETI, Dino (Org.) Estudos de língua falada: variações e confrontos. São Paulo: Humanitas Publicações. 1999. p. 109-130.

TORRES, Marisa. As cartas dos leitores no Público e no Diário de Notícias, FCSH Universidade Nova de Lisboa, Portugal, 2008.

WEINREICH, Uriel; LABOV, William; HERZOG, Marvim. Fundamentos empíricos para uma teoria da mudança linguística. Tradução de Marcos Bagno. São Paulo: Parábola, 2006. [Original em inglês].

Recebido em 28/08/2016 Aceito em 06/02/2017. 